Research Paper

\title{
The prevalence of small intestinal bacterial overgrowth in diabetes mellitus: a systematic review and meta-analysis
}

\author{
Xin Feng ${ }^{1}$, Xiao-Qing $\mathbf{L i}^{2, \&}$ \\ ${ }^{1}$ Department of Gastroenterology, The People's Hospital of Yubei District of Chongqing City, Chongqing 401120, \\ China \\ ${ }^{2}$ Department of Gastroenterology, Chongqing University Cancer Hospital, Shapingba, Chongqing 400030, China \\ Correspondence to: Xiao-Qing Li; email: 709682810@qq.com, https://orcid.org/0000-0002-9925-6764 \\ Keywords: small intestinal bacterial overgrowth, diabetes mellitus \\ Received: October 18, $2021 \quad$ Accepted: January 21, $2022 \quad$ Published: January 27, 2022
}

Copyright: (c) 2022 Feng and Li. This is an open access article distributed under the terms of the Creative Commons Attribution License (CC BY 3.0), which permits unrestricted use, distribution, and reproduction in any medium, provided the original author and source are credited.

\section{ABSTRACT}

Objective: We conducted this systematic review and meta-analysis to estimate the prevalence of SIBO in diabetic patients and to determine the association between SIBO and diabetes.

Methods: A comprehensive literature search of the PubMed, Cochrane Library and EMBASE databases from inception to June $\mathbf{2 0 2 1}$ was conducted for studies correlating SIBO with diabetes. Studies were screened, and relevant data were extracted and analysed. The pooled prevalence of SIBO among diabetic patients and the odds ratio of SIBO among diabetic patients compared with controls were calculated.

Results: Fourteen studies including 1417 diabetic patients and 649 controls met the inclusion criteria. The pooled prevalence of SIBO in diabetes was $29 \%$ (95\% Cl 20-39\%). The odds ratio of SIBO in diabetic patients was 2.91 (95\% Cl 0.82-10.32, p=0.1) compared with controls. Subgroup analyses showed that the prevalence of SIBO in diabetes was higher in studies using jejunal aspirate culture for diagnosis (39\%, 95\% $\mathrm{Cl} 12-66 \%)$ than in those using the lactulose breath test $(31 \%, 95 \% \mathrm{Cl} 18-43 \%)$ or glucose breath test $(29 \%, 95 \% \mathrm{Cl} 14-43 \%)$. The prevalence of SIBO in diabetes was higher in studies conducted in Western countries (35\%, 95\% Cl 21-49\%) than in those conducted in Eastern countries (24\%, 95\% Cl 14-34\%), and the prevalence of SIBO in type 1 diabetes (25\%, 95\% Cl $14 \%-36 \%)$ was not significantly different from that in type 2 diabetes $(30 \%, 95 \% \mathrm{Cl} 13 \%-47 \%)$.

Conclusions: Twenty-nine percent of diabetic patients tested positive for SIBO, and the risk of SIBO in diabetic patients was 2.91 times higher than that in patients without diabetes. Diabetes could be a predisposing factor for the development of SIBO, especially among patients diagnosed by jejunal aspirate culture or those in Western populations.

\section{INTRODUCTION}

Small intestinal bacterial overgrowth (SIBO) is defined as the presence of excessive numbers of bacteria and/or abnormal types of bacteria in the small bowel, causing gastrointestinal symptoms that include malnutrition, diarrhoea and abdominal distension [1]. The normal intestinal microbial balance is maintained by many important mechanisms that include gastric acid secretion, anatomical integrity of the digestive tract, propulsive peristaltic activity, and secretory $\operatorname{IgA}$ immunoglobulins [2]. Failure of these mechanisms can be responsible for the development of SIBO. The gold standard for diagnosing SIBO is jejunal aspirate culture (JAC). Alternatively, the breath test, a widely used method for diagnosing SIBO, has the advantages of being simple, non-invasive and easily acceptable. Recent studies have shown that SIBO is closely associated with various diseases, including Crohn's disease [3], irritable bowel syndrome [4], functional 
dyspepsia [5], hepatic encephalopathy [6], and nonalcoholic fatty liver disease [7].

Diabetes mellitus (DM) is a serious and growing global public health burden [8]. DM was estimated to affect at least 382 million people worldwide in 2013, and this number will rise to 592 million by the year 2035 [9]. DM is a metabolic disease characterized by hyperglycaemia, which can cause multiple-organ damage. Gastrointestinal complications are common among patients with DM [10,11]. Diabetes patients have been reported to exhibit increased risks of SIBO [12], but several studies have reported inconsistent results [13, 14]. Therefore, we conducted a systematic review and meta-analysis to investigate the relationship between $\mathrm{DM}$ and the risk of SIBO.

\section{MATERIALS AND METHODS}

This meta-analysis was conducted in accordance with the Preferred Reporting Items for Systematic reviews and Meta-Analyses (PRISMA) recommendations [15].

\section{Search strategy}

We searched the PubMed, Cochrane Library and EMBASE databases from their inception to June 2021 using the following search terms: (diabetes mellitus OR diabetes OR diabetic OR T1DM OR T2DM) AND (small intestinal bacterial overgrowth $\mathrm{OR}$ small intestine bacterial overgrowth OR SIBO OR small bowel bacterial overgrowth OR breath test OR SBBO). The literature search had no language restrictions. We also screened the reference lists of the included studies and relevant reviews to identify all eligible articles. Two reviewers (X. Feng and XQ. Li) independently performed the literature search.

\section{Study selection}

Articles were eligible if they met the following criteria: (a) cohort studies, case-control studies or crosssectional studies investigating the relationship between SIBO and DM; (b) subjects > 18 years old; (c) studies that recruited subjects meeting the DM diagnostic criteria; (d) valid methods used to assess SIBO, including the lactulose breath test (LBT), glucose breath test (GBT) or JAC; and (e) studies available in a fulltext format. We excluded articles such as case reports, review articles, letters and those reporting animal research. In addition, we excluded studies that provided duplicate data. We did not determine the cut-off values for a positive test as long as the positive criteria were clarified. When a study used more than one test to diagnose SIBO, we extracted data from each method separately.

\section{Data extraction and quality assessment}

Two reviewers (X. Feng and XQ. Li) independently extracted the following data from the included studies: first author's surname, year of publication, origin of study, study design, diagnostic test for SIBO, SIBO diagnostic criteria, prevalence of SIBO in DM, type of diabetes (type 1 , type 2 or both), average age, sex, and course of diabetes. Any discrepancies between the two reviewers were resolved by a third author (Z. Jiang). Two reviewers (X. Feng and XQ. Li) independently evaluated the quality of the cohort studies or case-control studies with the Newcastle-Ottawa Scale (NOS) [16] and assessed the quality of the cross-sectional studies with the modified Newcastle-Ottawa Scale [17]. Studies with a score $\geq 7$ were considered to be of high quality, while those with a score $<7$ were considered to be of low quality.

\section{Statistical analysis}

The pooled prevalence of SIBO in diabetic patients was calculated. Subgroup analyses were conducted by SIBO diagnostic tests (LBT vs. GBT vs. JAC), geographic areas (Western countries vs. Eastern countries) and type of diabetes (type 1 [T1DM] vs. type 2 [T2DM]). For cohort studies or case-control studies, the number of patients with SIBO in the case group and control group was calculated separately, and the odds ratios (ORs) and 95\% confidence intervals (CIs) for the prevalence of SIBO in diabetic patients and their respective controls were then calculated. $\mathrm{P}$ values $<0.05$ were considered statistically significant. We used the Cochran Q statistic and $\mathrm{I}^{2}$ statistic to assess heterogeneity. An $\mathrm{I}^{2}$ value $>50 \%$ or a $\mathrm{P}$ value $<0.10$ indicated statistically significant heterogeneity. The random-effects model was used with statistically significant heterogeneity; otherwise, the fixed-effects model was used. Furthermore, we used Egger's test and funnel plot and a risk of bias graph to assess any potential publication bias. $\mathrm{P}>0.05$ in Egger's test was considered to indicate no publication bias. We also performed sensitivity analyses by omitting one study in turn, which investigated the effect of an individual study on the overall prevalence of SIBO. All statistical analyses were performed using R 3.5.3 or RevMan 5.3.

\section{Ethics approval and consent to participate}

The manuscript has been read and approved by all of the authors, and the requirements for authorship, as stated earlier in this document, have been met.

\section{Availability of data and material}

The data and material are available from the corresponding author upon request. 


\section{RESULTS}

The initial literature search revealed 2629 potentially relevant studies (815 from PubMed, 1422 from EMBASE and 392 from Cochrane Library). Two studies were added by hand-searching the references from the included studies. We excluded 661 duplicates. Subsequently, we excluded 1925 studies that did not meet our inclusion criteria, which resulted in a full-text review of 45 studies. Twenty articles that did not report outcomes of interest were excluded, and 10 articles were excluded because they were not fulltext articles. One article was excluded because it duplicated data from another. Finally, 14 studies [1214, 18-28] (9 cohort studies and 5 cross-sectional studies), including 2066 participants (1417 diabetics and 649 controls), were included in this meta-analysis
(Figure 1). Since two different diagnostic tests for SIBO were performed with different results in one study [28], we separately calculated the prevalence of SIBO in two different studies. The characteristics and quality evaluation of the included studies are shown in Supplementary Table 1. All 14 articles were of high quality.

\section{Prevalence of SIBO in diabetic patients}

The prevalence of SIBO in diabetic patients was reported in all included studies [12-14, 18-28] and ranged from $8 \%$ to $75 \%$. The pooled prevalence of SIBO was $29 \%$ (95\% CI 20\%-39\%), with considerable heterogeneity $\left(\mathrm{I}^{2}=92 \%\right)$ (Figure 2$)$. We used a randomeffects model. The results of Egger's test showed that there was no publication bias $(\mathrm{P}>0.05)$ (Figure 3).
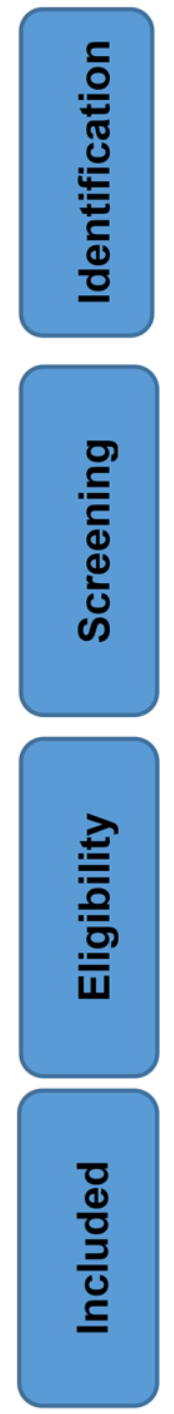

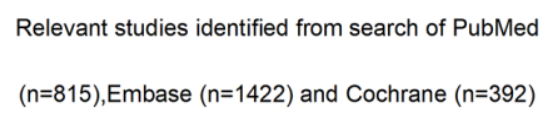

Relevant studies identified from search of PubMed

$(n=815)$, Embase $(n=1422)$ and Cochrane $(n=392)$

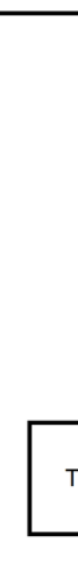

Additional studies identified through other sources

(handsearching of the reference lists) $(n=2)$

Title and abstract reviewed of potentially relevant studies $(n=1970)$

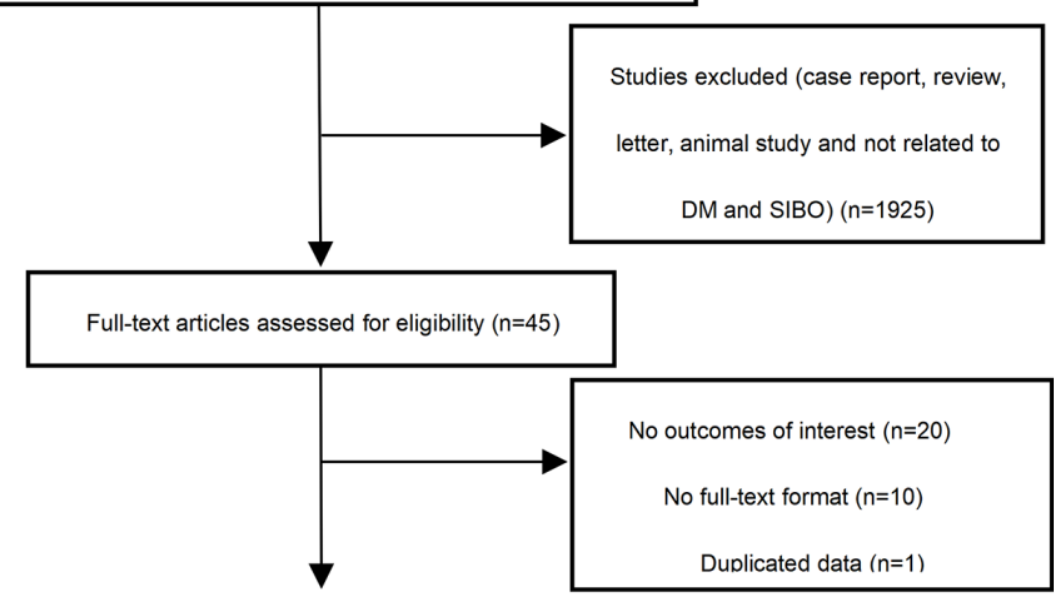

Studies included in the meta-analysis $(n=14)$

Figure 1. Flow chart of the selection process of articles. 
Study

Yan 2020

Malik 2020

Radionova 2020

Malik 2018

Rana 2017

Adamska 2016

Adamska 2015

Faria 2013

Rana 2011

Ojetti 2009

Urita 2006

Zietz 2000

Spengler 1989

Dooley 1988 LBT

Dooley 1988 JAC

Fixed effect model

Random effects model

Heterogeneity: $I^{2}=92 \%, \tau^{2}=0.6947, p<0.01$
Events Total

$\begin{array}{ll}56 & 104\end{array}$

$43 \quad 300$

$69 \quad 92$

$17 \quad 75$

$26 \quad 175$

$\begin{array}{ll}56 & 148\end{array}$

82200

326

$13 \quad 84$

1350

$21 \quad 82$

$17 \quad 50$

1019

$\begin{array}{ll}1 & 12 \\ 3 & 12\end{array}$

1429

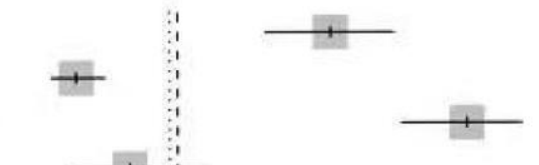

Proportion

$95 \%-\mathrm{Cl}$

$0.54[0.44 ; 0.64]$

$0.14[0.11 ; 0.19]$

$0.75[0.65 ; 0.83]$

$0.23[0.14 ; 0.34]$

$0.15[0.10 ; 0.21]$

$0.38[0.30 ; 0.46]$

$0.41[0.34 ; 0.48]$

$0.12[0.02 ; 0.30]$

$0.15[0.09 ; 0.25]$

$0.26[0.15 ; 0.40]$

$0.26[0.17 ; 0.36]$

$0.34[0.21 ; 0.49]$

$0.53[0.29 ; 0.76]$

$0.08[0.00 ; 0.38]$

$0.25[0.05 ; 0.57]$

$0.30[0.28 ; 0.33]$

$0.29[0.20 ; 0.39]$

\section{$\begin{array}{llll}0.2 & 0.4 & 0.6 & 0.8\end{array}$}

Figure 2. Forest plot of the pooled prevalence of SIBO in DM.

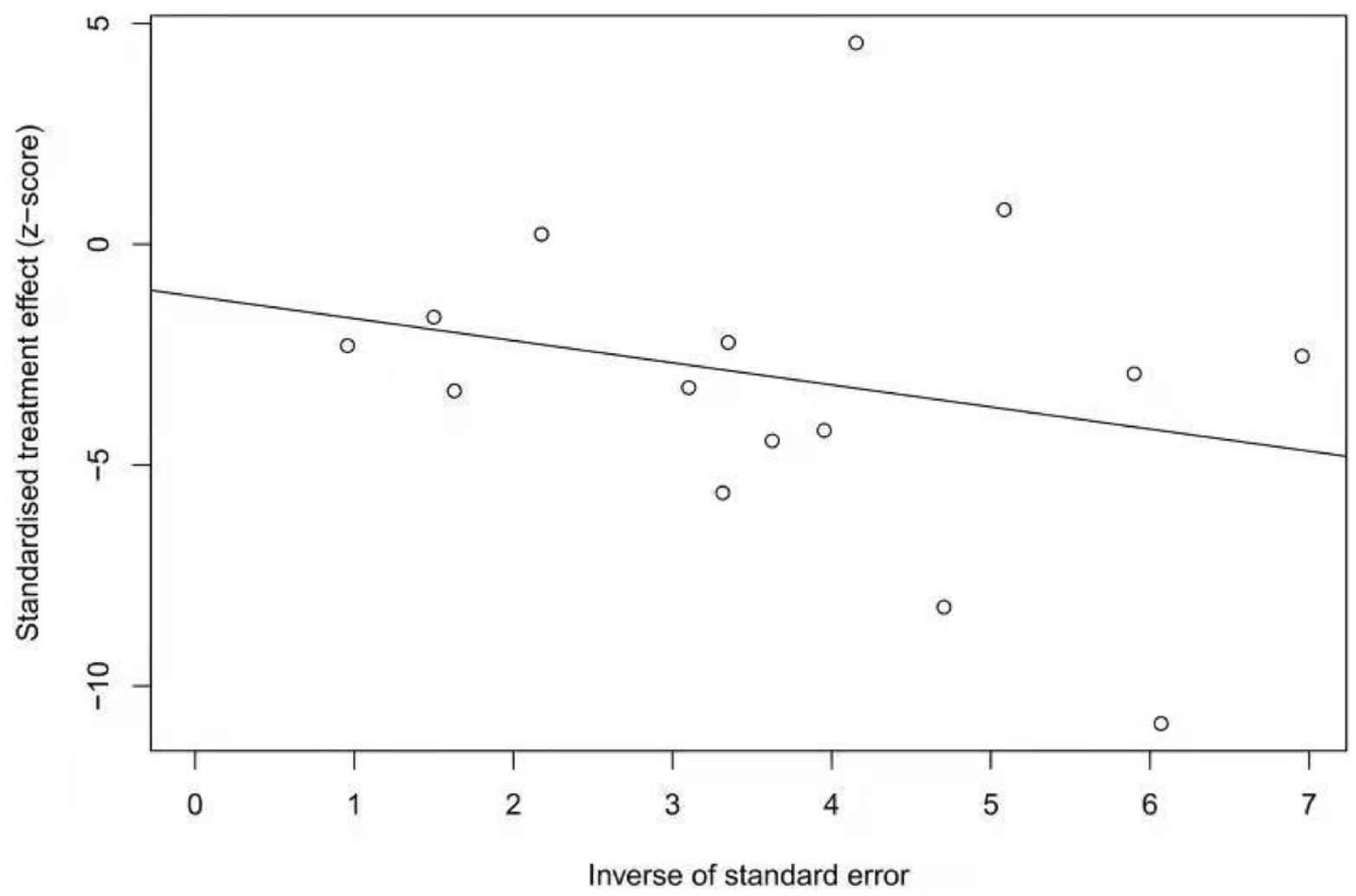

Figure 3. Egger test showing the publication bias of the pooled prevalence of SIBO in DM ( $p=0.6137)$. 
The studies were subgrouped based on the SIBO diagnostic test used. The prevalence of SIBO was $31 \%$ (95\% CI 18\%-43\%) in six studies [13, 14, 18, 22, 24, 28] using the LBT and $29 \%$ (95\% CI 14\%-43\%) in seven studies [12, 19-21, 23, 25, 26] using the GBT. Two studies [27, 28] using JAC showed a prevalence of 39\% (95\% CI 12\%-66\%) (Figure 4). When subgrouped by geographic area, the prevalence of SIBO was 35\% (95\% CI 21\%-49\%) in eight studies [13, 14, 19, 22, 24, 26-28] from Western countries and 24\% (95\% CI 14\%-34\%) in six studies [12, 18, 20, 21, 23, 25] from Eastern countries (Figure 5). Furthermore, in subgroup analysis based on the type of diabetes, the prevalence of SIBO in type 2 diabetes $(30 \%, 95 \%$ CI 13\%-47\%) [12, 18, 19, 21, 23, $28]$ was similar to the prevalence in type 1 diabetes $(25 \%$, 95\% CI 14\%-36\%) [13, 20, 22, 24]. The prevalence of
SIBO in studies including both type 1 and type 2 diabetes $[14,26]$ was $40 \%(95 \%$ CI 33\%-46\%) (Figure 6).

\section{SIBO in diabetic patients compared with controls}

Nine cohort studies [12-14, 19-21, 23, 27, 28] compared the event rate of SIBO between 1105 diabetic patients and 649 controls. The prevalence of SIBO among individuals with DM was higher than that among individuals without DM, with an OR of 2.91 (95\% CI 0.82-10.32), although the difference was not statistically significant $(\mathrm{p}=0.10)$ (Figure 7). We used random-effects models because of significant heterogeneity $\left(I^{2}=89 \%\right)$. The funnel plot indicated a possibility of publication bias (Figure 8). The risk of bias of these studies is graphed in Figure 9.

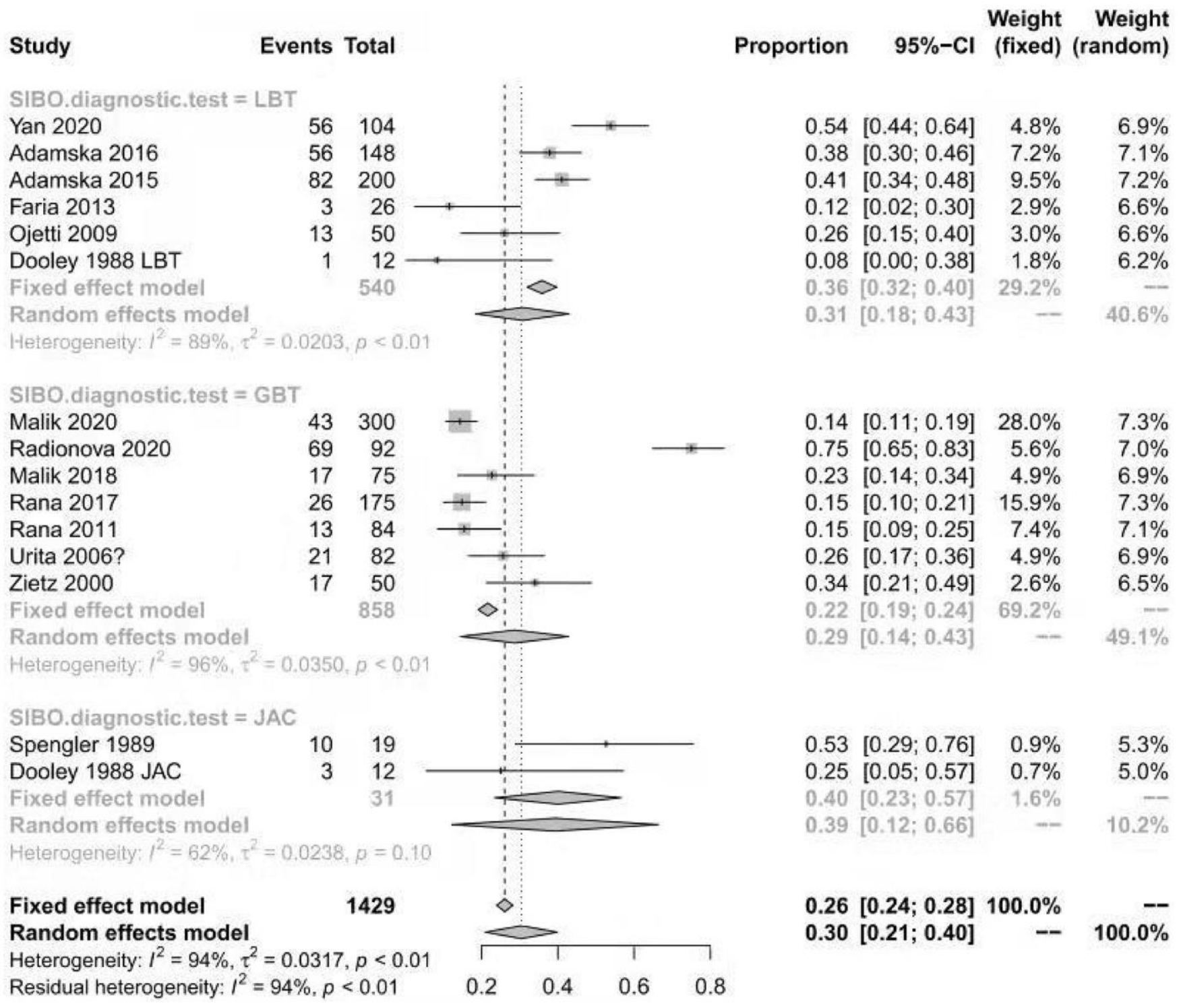

Figure 4. Forest plot of the prevalence of SIBO in DM based on the SIBO diagnostic test. 
Due to the significant heterogeneity, a sensitivity analysis was performed by excluding the study by Adamska et al. [13] from the meta-analysis. Exclusion of this study increased the pooled OR to 4.18 (95\% CI 1.34-13.05) and reached statistical significance $(\mathrm{p}=0.01)$. The between-study heterogeneity was decreased, with an $\mathrm{I}^{2}$ of $81 \%$. One reason is that almost half of the controls in the study were recruited from hospital personnel and their relatives, which may have affected the reliability of the results. Another reason is that both studies $[13,14]$ utilized the same laboratory database of the Poznan University of Medical Sciences during an overlapping period.

\section{DISCUSSION}

To the best of our knowledge, this study is the first systematic review and meta-analysis to investigate the association between DM and the risk of SIBO. Our meta-analysis revealed that (i) the overall pooled prevalence of SIBO in DM was 29\% (95\% CI 20\%$39 \%$ ), with the variability in SIBO prevalence depending on the type of SIBO diagnostic test and geographic area, and that (ii) the risk of SIBO was 2.91fold higher among individuals with DM than among individuals without DM.

Mechanisms between DM and SIBO have not been well elucidated. On the one hand, autonomic neuropathy is a common complication in diabetic patients, and it occurs throughout the whole gastrointestinal tract, affecting gastrointestinal motility [29, 30]. Dysfunction of the vagus nerve and intrinsic intestinal autonomic nerves may aggravate gastrointestinal autonomic neuropathy [30]. Gastrointestinal hypomotility due to diabetic autonomic neuropathy can result in small bowel stasis, thereby increasing the likelihood of SIBO. Ojetti et al. [24] found that diabetes patients with autonomic neuropathy have a significantly higher prevalence of SIBO than those without autonomic neuropathy. In

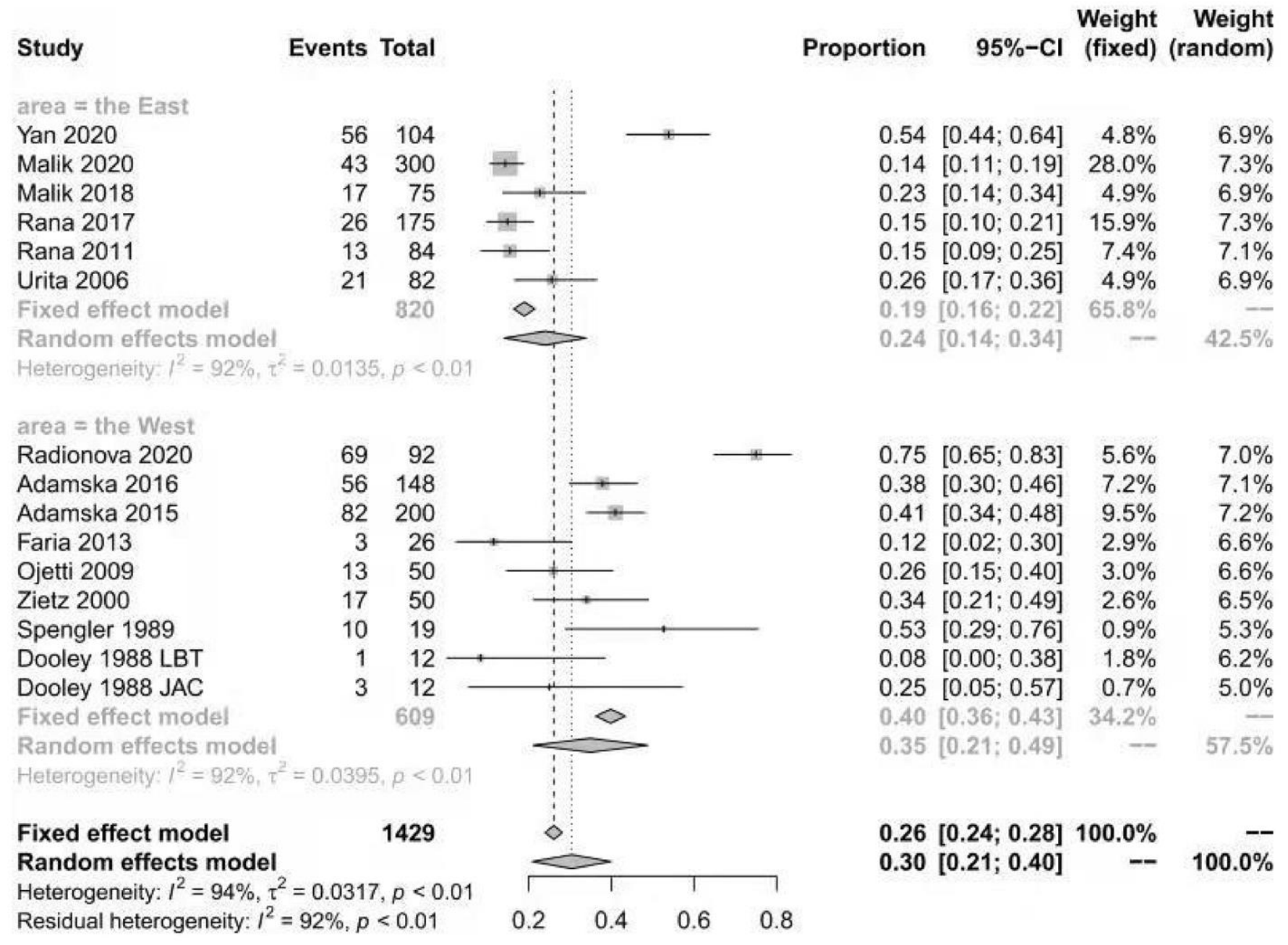

Figure 5. Forest plot of the prevalence of SIBO in DM based on geographic areas. 
addition, oxidative stress and inflammatory cytokines have been demonstrated in previous studies to accelerate the progression of diabetes [31, 32]. Some studies have reported that the levels of inflammatory cytokines (such as IL-6, TNF- $\alpha$, and IL-10) and oxidative stress-related parameters are significantly higher in both T1DM patients and T2DM patients than in controls [12, 20, 33-40]. In addition, Malik et al. observed that SIBO-positive T2DM patients have a significantly higher level of inflammatory cytokines and oxidative stress than SIBO-negative patients [12]. One explanation is that increased oxidative stress in diabetic patients may result in increased apoptosis of the inhibitory neuronal subpopulation of enteric neurons, which slows gut motility and makes patients more prone to SIBO [41]. On the other hand, SIBO seems to have some impact on diabetic patients. A study by Yan et al. [18] indicated that T2DM patients with SIBO showed worse glycaemic control and a lower level of insulin release than those without SIBO. Similar conclusions were reported in another study in non-alcoholic steatohepatitis (NASH), which indicated that NASH patients with SIBO have a higher prevalence of impaired glucose tolerance than those without SIBO [42]. These results suggest that SIBO could disrupt beta-cell function, although the mechanism remains unclear. One of the hypotheses is that activation of inflammatory pathways reduces insulin secretion by islet cells [43]. Malnutrition and gastrointestinal symptoms are also characteristics of diabetic patients with SIBO. Rana et al. found that urinary $\mathrm{d}$-xylose and lactose intolerance in SIBO-positive T2DM patients was more severe than that in SIBO-negative patients [21]. This indicated that SIBO may aggravate malabsorption and malnutrition and cause various gastrointestinal symptoms. These results were consistent with a study by Yan et al. [18], which showed

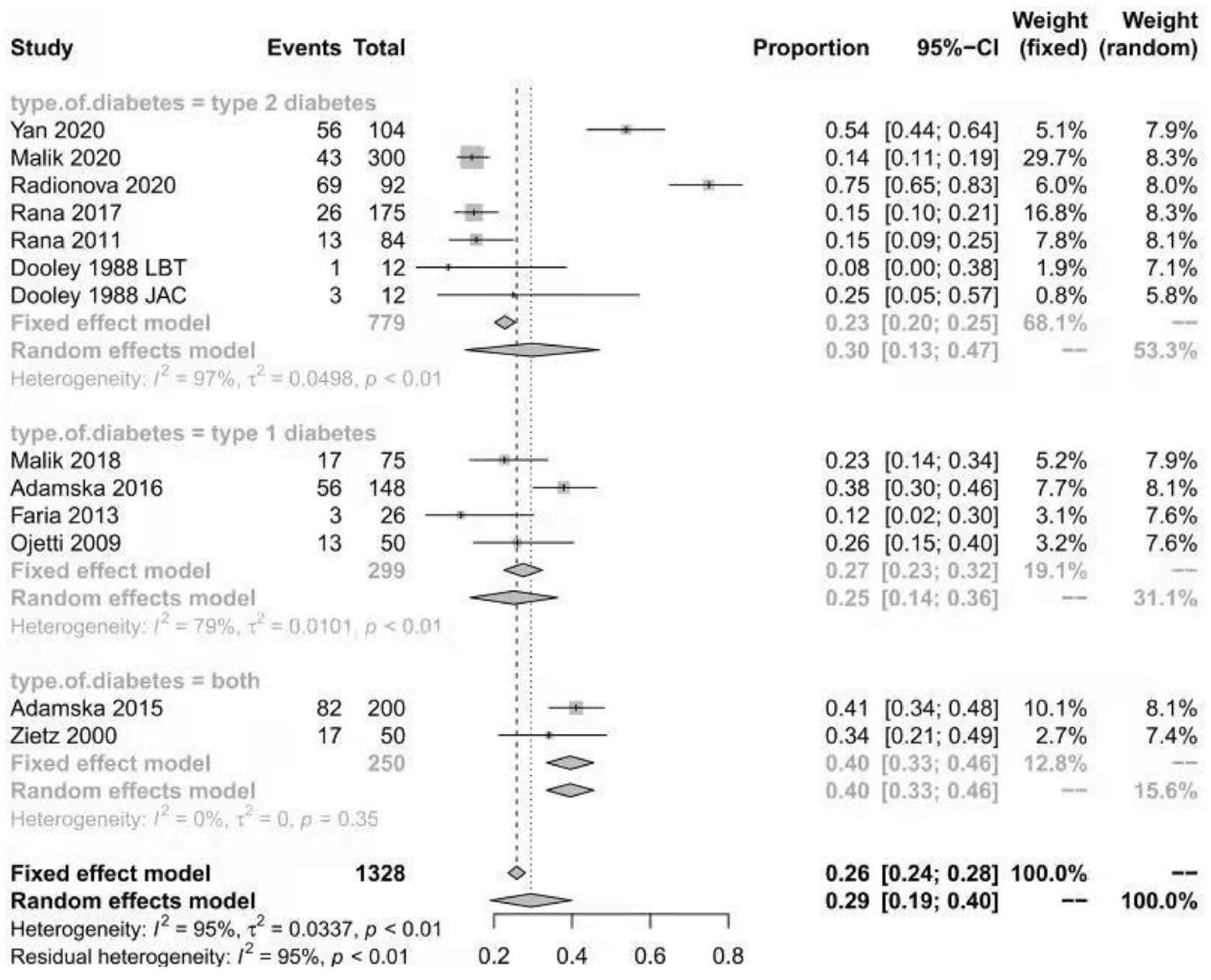

Figure 6. Forest plot of the prevalence of SIBO in DM based on type of diabetes. 
that T2DM subjects with SIBO had a significantly lower BMI than subjects without SIBO. Malabsorption in SIBO-positive patients might aggravate weight loss [44].

The pooled prevalence of SIBO in patients with DM was $29 \%$ in our study. The discrepancies in SIBO prevalence in these studies may be a result of the different SIBO diagnostic tests used and geographic areas. SIBO is a condition in which the small bowel is colonized by excessive numbers of aerobic and anaerobic microbes that are normally found in the large intestine $[45,46]$. The gold standard for diagnosing SIBO has long been JAC, although standardized techniques for aseptic collection of intestinal aspirate samples are lacking $[45,47]$. The North

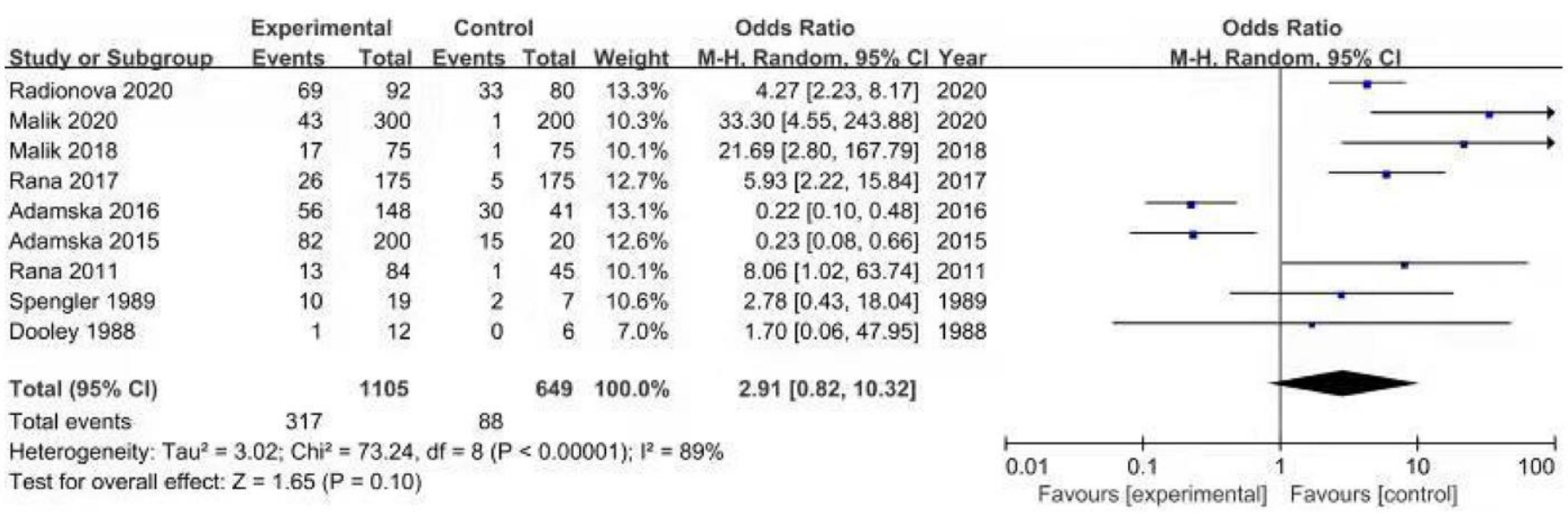

Figure 7. Forest plot of odds ratios of SIBO in diabetes patients compared with controls.

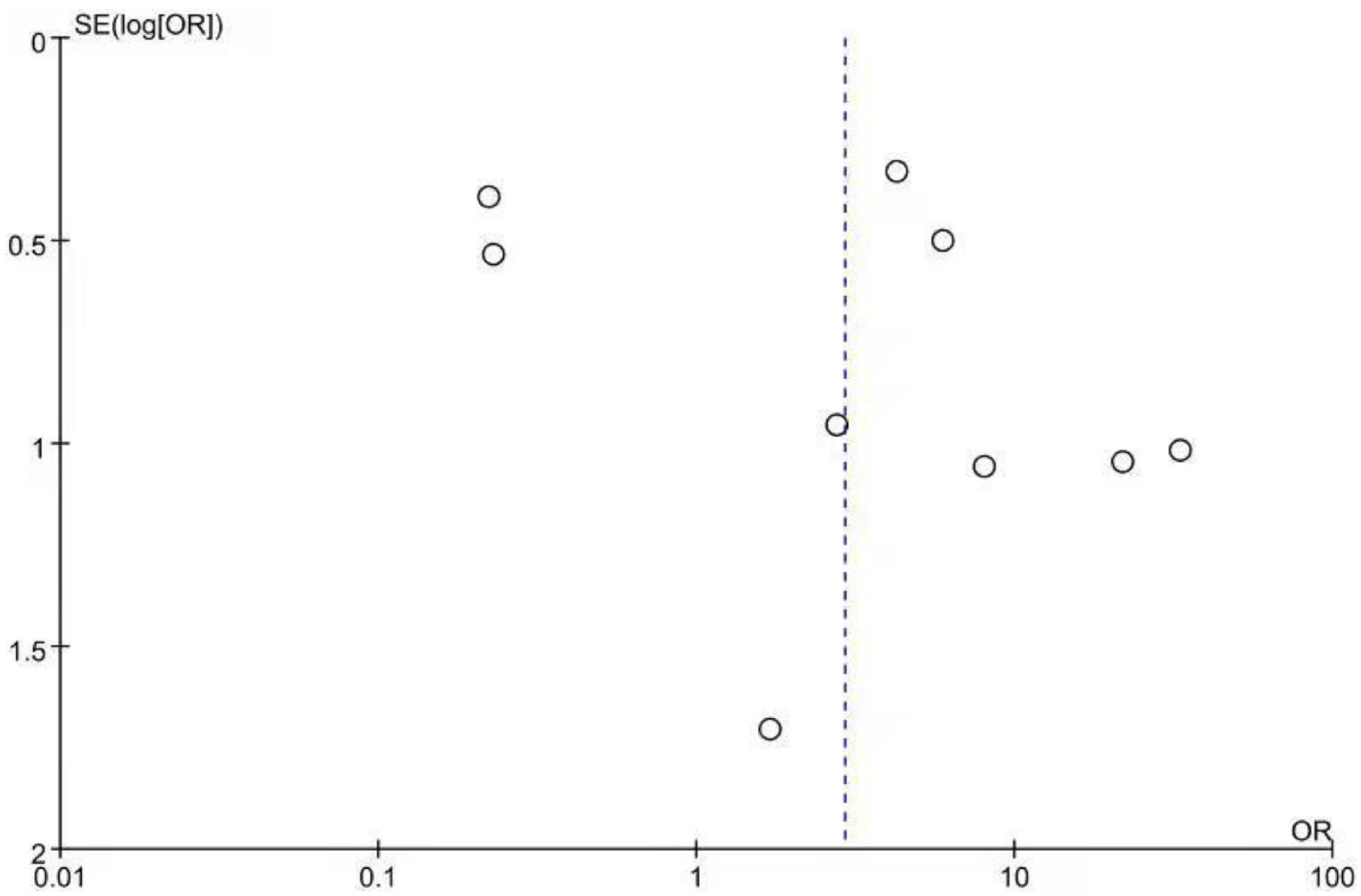

Figure 8. Funnel plot showing the publication bias of odds ratios of SIBO. 
American Consensus suggests the threshold of $>10^{3}$ colony-forming units per milliliter (c.f.u./ml) for the definition of SIBO [47]. The limitations of JAC are its invasiveness, cost, difficulty accessing the distal small bowel, possible contamination by oral flora, and false negatives for obligate anaerobes [47-49]. Breath tests are non-invasive and inexpensive methods for evaluating SIBO compared to JAC. Carbohydrates are fermented by microbes in the gut to produce gas, which is absorbed into the bloodstream and then expired through the lungs [45, 47]. Breath tests include the LBT and GBT. Lactulose is a non-digestible disaccharide that reaches the colon before a rise in hydrogen or methane and has a higher falsepositive result [47, 50-52]. In contrast, glucose is a monosaccharide that is rapidly absorbed in the proximal small bowel, with a higher false-negative result if the bacteria occupy only the lower parts of the small intestine [2, 47, 52, 53]. According to The North American Consensus [47], the correct doses of lactulose and glucose for breath testing are $10 \mathrm{~g}$ and $75 \mathrm{~g}$, respectively. A rise of $\geq 20$ parts per million(ppm) above baseline in hydrogen within 90 minutes or a rise of $\geq 10 \mathrm{ppm}$ in methane should be considered positive for glucose and lactose breath testing, respectively [47]. In our study, the prevalence of SIBO diagnosed by LBT and GBT was lower than that diagnosed by JAC (31\% and $29 \%$ vs. $39 \%$ ). This result may be due to contamination with oral and oesophageal flora, resulting in a significant number of false-positive results. The different geographic areas may also account for the variance in reported SIBO prevalence rates in DM. We found that the SIBO prevalence in DM was higher in Western countries than in Eastern countries (35\% vs. $24 \%$ ). One possible explanation for this result is the differences in dietary habits in different countries. Highfat and carbohydrate-rich foods in Western countries can decrease beneficial gut microbes and increase total anaerobic microflora and counts of Bacteroides and Enterobacteriales [54]. Another explanation is the inherently different metabolism and physiology among different ethnic groups. In addition, we observed that the prevalence of SIBO in T1DM was not significantly different from that in T2DM (25\% vs. 30\%). This suggests that the type of diabetes is not significantly associated with the prevalence of SIBO. Data from the present study suggest that the risk of SIBO is almost three times higher in patients with DM than in controls, although the difference was not statistically significant. Two studies in this meta-analysis reported that the prevalence of SIBO in diabetic patients was lower than that in controls [13, 14], which was not consistent with other studies. One possible reason is that Adamska et al. [13] recruited controls from hospital personnel and their relatives, and all participants in the two studies [13, 14] were from the same medical institution. When we excluded the study by Adamska et al. [13], the risk of SIBO in DM increased to 4.18-fold compared with controls and reached statistical significance.

This study had several limitations: 1) a relatively small sample size due to the limited number of patients in each of the included studies; 2) the result of the funnel plot, which calculates the OR comparing the prevalence of SIBO in DM and controls, suggesting the possibility of publication bias; and 3) different diagnostic tests and different geographic areas of subjects that may have caused heterogeneity in the results.

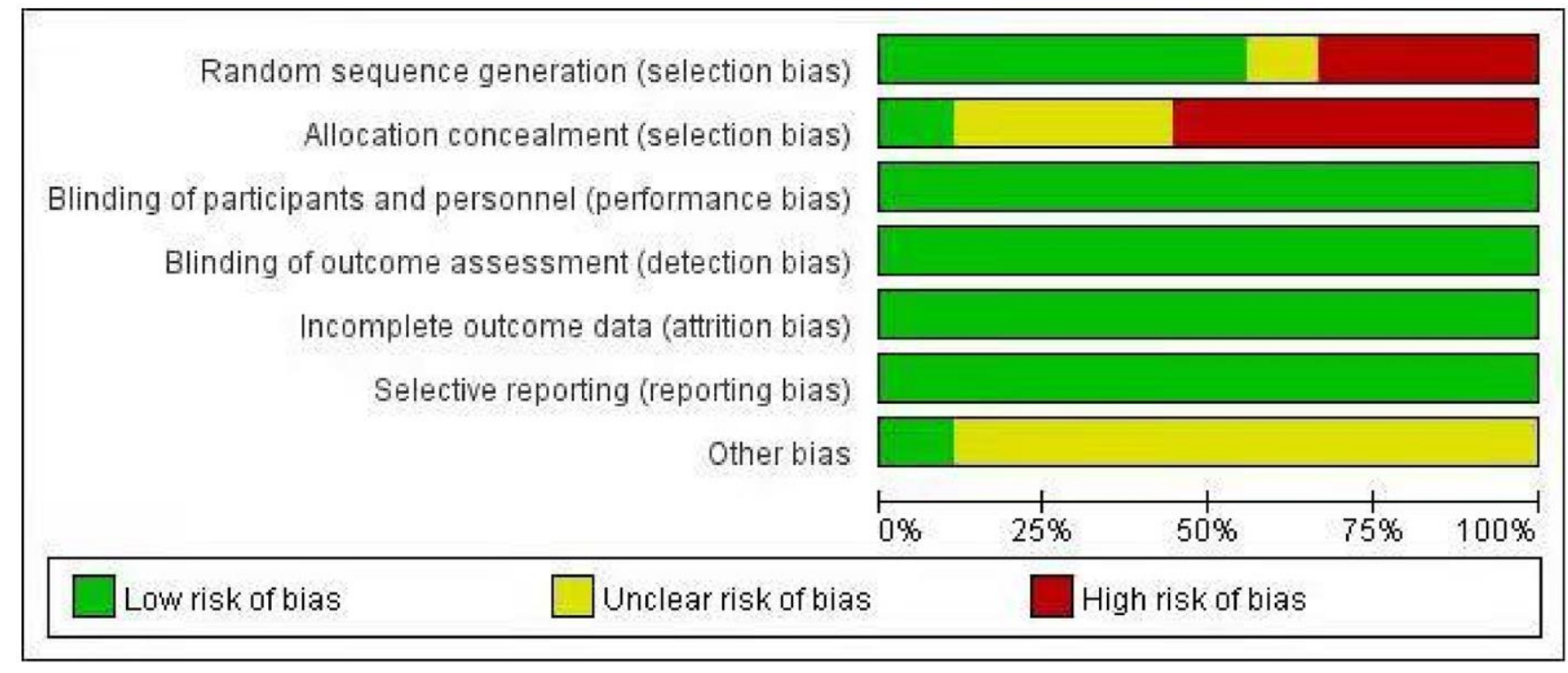

Figure 9. The risk of bias graph about odds ratios of SIBO. 


\section{CONCLUSIONS}

In summary, approximately $29 \%$ of diabetic patients tested positive for SIBO. The increased risk of SIBO appears to be greater in patients diagnosed by JAC or in Western populations. There was no significant difference in the prevalence of SIBO between T1DM and T2DM patients. The risk of SIBO in diabetic patients was 2.91 times higher than that in patients without diabetes. These results suggest that DM could be a predisposing factor for the development of SIBO.

\section{AUTHOR CONTRIBUTIONS}

Xiaoqing Li and Xin Feng designed the study. Xiaoqing $\mathrm{Li}$ and Xin Feng analysed the data and wrote the manuscript.

\section{CONFLICTS OF INTEREST}

The authors declare that they have no conflicts of interest.

\section{FUNDING}

This research received no specific grant from any funding agency in the public, commercial, or not-forprofit sectors.

\section{Editorial note}

\&This corresponding author has a verified history of publications using a personal email address for correspondence.

\section{REFERENCES}

1. Bures J, Cyrany J, Kohoutova D, Förstl M, Rejchrt S, Kvetina J, Vorisek V, Kopacova M. Small intestinal bacterial overgrowth syndrome. World J Gastroenterol. 2010; 16:2978-90.

https://doi.org/10.3748/wig.v16.i24.2978

PMID:20572300

2. Hammer HF, Fox MR, Keller J, Salvatore S, Basilisco G, Hammer J, Lopetuso L, Benninga $M$, Borrelli $O$, Dumitrascu D, Hauser B, Herszenyi L, Nakov R, et al, and European $\mathrm{H} 2-\mathrm{CH} 4$-breath test group. European guideline on indications, performance, and clinical impact of hydrogen and methane breath tests in adult and pediatric patients: European Association for Gastroenterology, Endoscopy and Nutrition, European Society of Neurogastroenterology and Motility, and European Society for Paediatric Gastroenterology Hepatology and Nutrition consensus. United European Gastroenterol J. 2021. [Epub ahead of print]. https://doi.org/10.1002/ueg2.12133

PMID:34431620

3. Bertges ER, Chebli JM. Prevalence and factors associated with small intestinal bacterial overgrowth in patients with Crohn's disease: a retrospective study at a referral center. Arq Gastroenterol. 2020; 57:283-88. https://doi.org/10.1590/S0004-2803.202000000-64 PMID: $\underline{3027485}$

4. Takakura W, Pimentel M. Small Intestinal Bacterial Overgrowth and Irritable Bowel Syndrome - An Update. Front Psychiatry. 2020; 11:664.

https://doi.org/10.3389/fpsyt.2020.00664 PMID: $\underline{32754068}$

5. Tziatzios G, Gkolfakis P, Papanikolaou IS, Mathur R, Pimentel M, Damoraki G, Giamarellos-Bourboulis EJ, Dimitriadis G, Triantafyllou K. High Prevalence of Small Intestinal Bacterial Overgrowth among Functional Dyspepsia Patients. Dig Dis. 2021; 39:382-90. https://doi.org/10.1159/000511944 PMID:33011725

6. Zhang $Y$, Feng $Y$, Cao B, Tian $Q$. The effect of small intestinal bacterial overgrowth on minimal hepatic encephalopathy in patients with cirrhosis. Arch Med Sci. 2016; 12:592-6.

https://doi.org/10.5114/aoms.2015.55675 PMID:27279853

7. Ghoshal UC, Goel A, Quigley EM. Gut microbiota abnormalities, small intestinal bacterial overgrowth, and non-alcoholic fatty liver disease: An emerging paradigm. Indian J Gastroenterol. 2020; 39:9-21. https://doi.org/10.1007/s12664-020-01027-w PMID: $\underline{2291578}$

8. Corriere $M$, Rooparinesingh $N$, Kalyani RR. Epidemiology of diabetes and diabetes complications in the elderly: an emerging public health burden. Curr Diab Rep. 2013; 13:805-13. https://doi.org/10.1007/s11892-013-0425-5 PMID:24018732

9. Guariguata L, Whiting DR, Hambleton I, Beagley J, Linnenkamp U, Shaw JE. Global estimates of diabetes prevalence for 2013 and projections for 2035. Diabetes Res Clin Pract. 2014; 103:137-49.

https://doi.org/10.1016/i.diabres.2013.11.002 PMID:24630390

10. Zawada AE, Moszak M, Skrzypczak D, Grzymisławski M. Gastrointestinal complications in patients with diabetes mellitus. Adv Clin Exp Med. 2018; 27:567-72. https://doi.org/10.17219/acem/67961 PMID:29533548

11. Du YT, Rayner CK, Jones KL, Talley NJ, Horowitz M. Gastrointestinal Symptoms in Diabetes: Prevalence, Assessment, Pathogenesis, and Management. Diabetes Care. 2018; 41:627-37. 
https://doi.org/10.2337/dc17-1536 PMID:29463666

12. Malik A, Morya RK, Saha S, Singh PK, Bhadada SK, Rana SV. Oxidative stress and inflammatory markers in type 2 diabetic patients. Eur J Clin Invest. 2020; 50:e13238. https://doi.org/10.1111/eci.13238 PMID: $\underline{32298466}$

13. Adamska A, Nowak M, Piłaciński S, Araszkiewicz A, Litwinowicz $M$, Tomaszewska $M$, Wierusz-Wysocka B, Grzymisławski M, Zozulińska-Ziółkiewicz D. Small intestinal bacterial overgrowth in adult patients with type 1 diabetes: its prevalence and relationship with metabolic control and the presence of chronic complications of the disease. Pol Arch Med Wewn. 2016; 126:628-34. https://doi.org/10.20452/pamw.3501 PMID:27535109

14. Adamska A, Nowak M, Piłaciński S, Araszkiewicz A, Litwinowicz $M$, Tomaszewska $M$. The prevalence incidence of small intestinal bacterial overgrowth (SIBO) in patients with diabetes. Diabetologia Kliniczna. 2015; 4:175-82. https://doi.org/10.5603/DK.2015.0020

15. Moher D, Liberati A, Tetzlaff J, Altman DG, and PRISMA Group. Preferred reporting items for systematic reviews and meta-analyses: the PRISMA statement. PLoS Med. 2009; 6:e1000097. https://doi.org/10.1371/journal.pmed.1000097 PMID:19621072

16. Wells G. The Newcastle-Ottawa Scale (NOS) for Assessing the Quality of Non-Randomised Studies in Meta-Analyses[C]// Symposium on Systematic Reviews: Beyond the Basics. 2014.

17. Moga C, Bing G, Schopflocher D, Harstall C. Development of a quality appraisal tool for case series studies using a modified Delphi technique. Edmonton, AB: Institute of Health Economics. 2012.

18. Yan LH, Mu B, Pan D, Shi YN, Yuan JH, Guan Y, Li W, Zhu XY, Guo L. Association between small intestinal bacterial overgrowth and beta-cell function of type 2 diabetes. J Int Med Res. 2020; 48:300060520937866. https://doi.org/10.1177/0300060520937866 PMID: $\underline{32691685}$

19. Radionova TO, Skrypnyk IM, Maslova GS. Do H. Pylori status and small intestinal bacterial overgrowth determine the clinical course of chronic active gastritis in patients with type 2 diabetes mellitus? Wiad Lek. 2020; 73:1223-8.

https://doi.org/10.36740/WLek202006127

PMID:32723957

20. Malik A, Morya RK, Bhadada SK, Rana S. Type 1 diabetes mellitus: Complex interplay of oxidative stress, cytokines, gastrointestinal motility and small intestinal bacterial overgrowth. Eur J Clin Invest. 2018; 48:e13021.

https://doi.org/10.1111/eci.13021 PMID:30155878

21. Rana SV, Malik A, Bhadada SK, Sachdeva N, Morya RK, Sharma G. Malabsorption, Orocecal Transit Time and Small Intestinal Bacterial Overgrowth in Type 2 Diabetic Patients: A Connection. Indian J Clin Biochem. 2017; 32:84-9. https://doi.org/10.1007/s12291-016-0569-6 PMID:28149017

22. Faria M, Pavin EJ, Parisi MC, Lorena SL, Brunetto SQ, Ramos CD, Pavan CR, Mesquita MA. Delayed small intestinal transit in patients with long-standing type 1 diabetes mellitus: investigation of the relationships with clinical features, gastric emptying, psychological distress, and nutritional parameters. Diabetes Technol Ther. 2013; 15:32-8. https://doi.org/10.1089/dia.2012.0158 PMID:23126582

23. Rana S, Bhansali A, Bhadada S, Sharma S, Kaur J, Singh K. Orocecal transit time and small intestinal bacterial overgrowth in type 2 diabetes patients from North India. Diabetes Technol Ther. 2011; 13:1115-20.

https://doi.org/10.1089/dia.2011.0078

PMID:21770765

24. Ojetti V, Pitocco D, Scarpellini E, Zaccardi F, Scaldaferri F, Gigante G, Gasbarrini G, Ghirlanda G, Gasbarrini A. Small bowel bacterial overgrowth and type 1 diabetes. Eur Rev Med Pharmacol Sci. 2009; 13:419-23.

PMID:20085122

25. Urita $\mathrm{Y}$, Ishihara $\mathrm{S}$, Akimoto $\mathrm{T}$, Kato $\mathrm{H}$, Hara $\mathrm{N}$, Honda $\mathrm{Y}$, Nagai $Y$, Nakanishi K, Shimada N, Sugimoto M, Miki K. Seventy-five gram glucose tolerance test to assess carbohydrate malabsorption and small bowel bacterial overgrowth. World J Gastroenterol. 2006; 12:3092-5. https://doi.org/10.3748/wjg.v12.i19.3092 PMID:16718794

26. Zietz B, Lock G, Straub RH, Braun B, Schölmerich J, Palitzsch KD. Small-bowel bacterial overgrowth in diabetic subjects is associated with cardiovascular autonomic neuropathy. Diabetes Care. 2000; 23:1200-1.

https://doi.org/10.2337/diacare.23.8.1200 PMID:10937525

27. Spengler U, Stellaard F, Ruckdeschel G, Scheurlen C, Kruis W. Small intestinal transit, bacterial growth, and bowel habits in diabetes mellitus. Pancreas. 1989; 4:65-70. https://doi.org/10.1097/00006676-198902000-00010 PMID:2717603

28. Dooley CP, el Newihi HM, Zeidler A, Valenzuela JE. Abnormalities of the migrating motor complex in diabetics with autonomic neuropathy and diarrhea. 
Scand J Gastroenterol. 1988; 23:217-23. https://doi.org/10.3109/00365528809103971 PMID:3363294

29. Ozturk NA, Gokturk HS, Demir M, Erdogan D, Unler GK, Gur G, Yilmaz U. The effect of autonomous neuropathy on bowel preparation in type 2 diabetes mellitus. Int J Colorectal Dis. 2009; 24:1407-12.

https://doi.org/10.1007/s00384-009-0757-4 PMID: 19582466

30. Freeman R. Diabetic autonomic neuropathy. Handb Clin Neurol. 2014; 126:63-79.

https://doi.org/10.1016/B978-0-444-53480-4.00006-0 PMID:25410215

31. Fatima N, Faisal SM, Zubair S, Ajmal M, Siddiqui SS, Moin S, Owais M. Role of Pro-Inflammatory Cytokines and Biochemical Markers in the Pathogenesis of Type 1 Diabetes: Correlation with Age and Glycemic Condition in Diabetic Human Subjects. PLoS One. 2016; 11:e0161548.

https://doi.org/10.1371/journal.pone.0161548

PMID:27575603

32. Biswas SK. Does the Interdependence between Oxidative Stress and Inflammation Explain the Antioxidant Paradox? Oxid Med Cell Longev. 2016; 2016:5698931.

https://doi.org/10.1155/2016/5698931

PMID:26881031

33. Darko SN, Yar DD, Owusu-Dabo E, Awuah AA, Dapaah W, Addofoh N, Salifu SP, Awua-Boateng NY, Adomako-Boateng F. Variations in levels of IL- 6 and TNF- $\alpha$ in type 2 diabetes mellitus between rural and urban Ashanti Region of Ghana. BMC Endocr Disord. 2015; 15:50.

https://doi.org/10.1186/s12902-015-0047-9

PMID:26391589

34. Abbatecola AM, Ferrucci L, Grella R, Bandinelli $S$, Bonafè $M$, Barbieri $M$, Corsi AM, Lauretani $F$, Franceschi C, Paolisso G. Diverse effect of inflammatory markers on insulin resistance and insulinresistance syndrome in the elderly. J Am Geriatr Soc. 2004; 52:399-404.

https://doi.org/10.1111/j.1532-5415.2004.52112.x PMID:14962155

35. Hu FB, Meigs JB, Li TY, Rifai N, Manson JE. Inflammatory markers and risk of developing type 2 diabetes in women. Diabetes. 2004; 53:693-700.

https://doi.org/10.2337/diabetes.53.3.693

PMID:14988254

36. Al-Shukaili A, Al-Ghafri S, Al-Marhoobi S, Al-Abri S, AlLawati J, Al-Maskari M. Analysis of inflammatory mediators in type 2 diabetes patients. Int J Endocrinol. 2013; 2013:976810. https://doi.org/10.1155/2013/976810

PMID:23762057

37. Rodrigues KF, Pietrani NT, Bosco AA, Campos FM, Sandrim VC, Gomes KB. IL-6, TNF- $\alpha$, and IL-10 levels/polymorphisms and their association with type 2 diabetes mellitus and obesity in Brazilian individuals. Arch Endocrinol Metab. 2017; 61:438-46. https://doi.org/10.1590/2359-3997000000254 PMID:28225860

38. Reis JS, Amaral CA, Volpe CM, Fernandes JS, Borges EA, Isoni CA, Anjos PM, Machado JA. Oxidative stress and interleukin- 6 secretion during the progression of type 1 diabetes. Arq Bras Endocrinol Metabol. 2012; 56:441-8.

https://doi.org/10.1590/s0004-27302012000700006 PMID:23108749

39. He JS, Xie PS, Luo DS, Sun CJ, Zhang YG, Liu FX. Role of immune dysfunction in pathogenesis of type 1 diabetes mellitus in children. Asian Pac J Trop Med. 2014; 7:823-6. https://doi.org/10.1016/S1995-7645(14)60144-9 PMID:25129468

40. Bandeira Sde M, Guedes Gda S, da Fonseca $L$, Pires AS, Gelain DP, Moreira JC, Rabelo LA, Vasconcelos SM, Goulart MO. Characterization of blood oxidative stress in type 2 diabetes mellitus patients: increase in lipid peroxidation and SOD activity. Oxid Med Cell Longev. 2012; 2012:819310.

https://doi.org/10.1155/2012/819310 PMID:23259029

41. Kashyap P, Farrugia G. Oxidative stress: key player in gastrointestinal complications of diabetes. Neurogastroenterol Motil. 2011; 23:111-4. https://doi.org/10.1111/i.1365-2982.2010.01659.x PMID:21226884

42. Sajjad A, Mottershead M, Syn WK, Jones R, Smith S, Nwokolo CU. Ciprofloxacin suppresses bacterial overgrowth, increases fasting insulin but does not correct low acylated ghrelin concentration in nonalcoholic steatohepatitis. Aliment Pharmacol Ther. 2005; 22:291-9.

https://doi.org/10.1111/i.1365-2036.2005.02562.x PMID: 16097995

43. Wang X, Ge QM, Bian F, Dong Y, Huang CM. Inhibition of TLR4 protects rat islets against lipopolysaccharide-induced dysfunction. Mol Med Rep. 2017; 15:805-12.

https://doi.org/10.3892/mmr.2016.6097

PMID:28101570

44. Saltzman JR, Russell RM. Nutritional consequences of intestinal bacterial overgrowth. Compr Ther. 1994; 20:523-30. 
PMID: $\underline{7805370}$

45. Quigley EM, Murray JA, Pimentel M. AGA Clinical Practice Update on Small Intestinal Bacterial Overgrowth: Expert Review. Gastroenterology. 2020; 159:1526-32.

https://doi.org/10.1053/i.gastro.2020.06.090 PMID:32679220

46. Rezaie A, Pimentel M, Rao SS. How to Test and Treat Small Intestinal Bacterial Overgrowth: an EvidenceBased Approach. Curr Gastroenterol Rep. 2016; 18:8.

https://doi.org/10.1007/s11894-015-0482-9 PMID:26780631

47. Rezaie A, Buresi M, Lembo A, Lin H, McCallum R, Rao S, Schmulson M, Valdovinos M, Zakko S, Pimentel M. Hydrogen and Methane-Based Breath Testing in Gastrointestinal Disorders: The North American Consensus. Am J Gastroenterol. 2017; 112:775-84. https://doi.org/10.1038/ajg.2017.46 PMID:28323273

48. Aziz I, Törnblom H, Simrén M. Small intestinal bacterial overgrowth as a cause for irritable bowel syndrome: guilty or not guilty? Curr Opin Gastroenterol. 2017; 33:196-202.

https://doi.org/10.1097/MOG.0000000000000348 PMID:28257307

49. Ghoshal UC, Shukla R, Ghoshal U. Small Intestinal Bacterial Overgrowth and Irritable Bowel Syndrome: A Bridge between Functional Organic Dichotomy. Gut Liver. 2017; 11:196-208.

https://doi.org/10.5009/gnl16126 PMID:28274108

50. Therrien A, Bouchard S, Sidani S, Bouin M. Prevalence of Small Intestinal Bacterial Overgrowth among
Chronic Pancreatitis Patients: A Case-Control Study. Can J Gastroenterol Hepatol. 2016; 2016:7424831. https://doi.org/10.1155/2016/7424831 PMID:27446865

51. Yu D, Cheeseman F, Vanner S. Combined oro-caecal scintigraphy and lactulose hydrogen breath testing demonstrate that breath testing detects oro-caecal transit, not small intestinal bacterial overgrowth in patients with IBS. Gut. 2011; 60:334-40. https://doi.org/10.1136/gut.2009.205476 PMID:21112950

52. Ghoshal UC. How to interpret hydrogen breath tests. J Neurogastroenterol Motil. 2011; 17:312-7. https://doi.org/10.5056/jnm.2011.17.3.312 PMID:21860825

53. Saad RJ, Chey WD. Breath testing for small intestinal bacterial overgrowth: maximizing test accuracy. Clin Gastroenterol Hepatol. 2014; 12:1964-72. https://doi.org/10.1016/j.cgh.2013.09.055 PMID:24095975

54. Singh RK, Chang HW, Yan D, Lee KM, Ucmak D, Wong K, Abrouk M, Farahnik B, Nakamura M, Zhu TH, Bhutani T, Liao W. Influence of diet on the gut microbiome and implications for human health. J Transl Med. 2017; 15:73.

https://doi.org/10.1186/s12967-017-1175-y

PMID:28388917 


\section{SUPPLEMENTARY MATERIALS}

\section{Supplementary Table}

Please browse Full Text version to see the data of Supplementary Table 1.

Supplementary Table 1. Main characteristics of the studies included in this meta-analysis. 